Review

\title{
Positive anterior margins in breast conserving surgery: Does it matter? A systematic review of the literature
}

\author{
Su C. Ang ${ }^{\text {a, b }}$, Grace Tapia ${ }^{\text {b }}$, Emily J. Davidson ${ }^{\text {b }}$, Bora Kahramangil ${ }^{\text {c }}$, Cindy Mak ${ }^{\text {b }}$, \\ Hugh Carmalt ${ }^{\mathrm{b}}$, Sanjay Warrier ${ }^{\mathrm{b}, \mathrm{d}, *}$ \\ a Department of General Surgery, Royal Prince Alfred Hospital, Sydney, Australia \\ ${ }^{\mathrm{b}}$ Department of Breast Surgery, Chris Obrien Lifehouse, Australia \\ ${ }^{\mathrm{c}}$ Faculty of Medicine, Hacettepe University, Ankara, Turkey \\ ${ }^{\mathrm{d}}$ Royal Prince Alfred Hospital Academic Institute, Sydney, Australia
}

\section{A R T I C L E I N F O}

\section{Article history:}

Received 31 August 2015

Received in revised form

29 November 2015

Accepted 19 December 2015

Available online 6 April 2016

\section{Keywords:}

Breast surgery

Margins

Local recurrence

Wide local excision

\begin{abstract}
A B S T R A C T
Positive margins are associated with an increased risk of ipsilateral breast tumor recurrence (IBTR); therefore re-excision of positive margins is recommended. Involvement of anatomically non-breast margins, such as anterior margins, has been associated to a lower risk of IBTR than radial margins. Although many surgeons do not re-excise positive anterior margins (PAM); there is no consensus regarding this approach. The objective of this study is to find evidence that assesses this practice.

A systemic literature review was performed through six databases from January 1995 to July 2014. Studies that discussed anatomical location of involved margins in BCS were included.

Six studies were identified evaluating PAM. One study reported a $2.5 \%$ rate of IBTR in patients with non-negative margins treated with radiotherapy (of which $23 \%$ had a PAM). Another study showed $4 \%$ of residual disease after re-excision of PAM, but did not report IBTR rates. A later observational study reported that $87.5 \%$ of positive anterior and posterior margins were re-excised. One survey from America and one from the UK showed that $47 \%$ and $71 \%$ of surgeons would not re-excise PAM, respectively. A later survey in the UK reported that $43.8 \%$ of surgeons would not re-excise PAM in DCIS, whilst $29.2 \%$ would not for invasive carcinoma.

Common surgical practices to not re-excise PAM contradict current guidelines that recommend obtaining negative margins to reduce the risk of IBTR. However, there is little evidence detailing the relationship between PAM and IBTR rates. Low residual disease after re-excision of PAM supports the limited benefit of re-excise this margin; however further studies are required to evaluate this topic.
\end{abstract}

(c) 2016 Elsevier Ltd. All rights reserved.

\section{Contents}

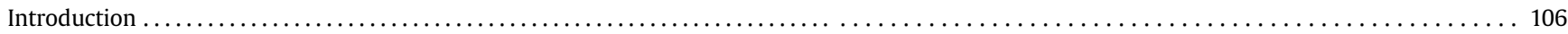

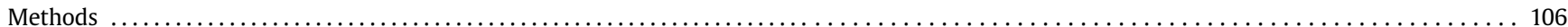

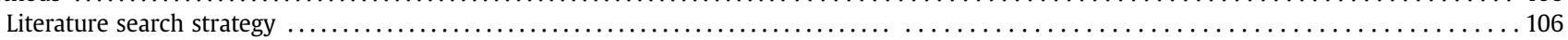

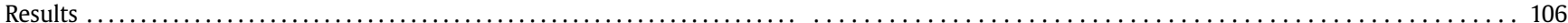

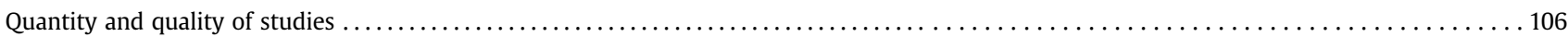

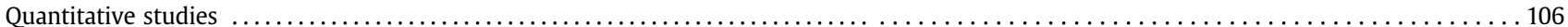

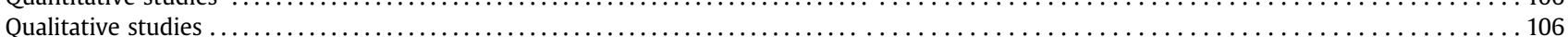

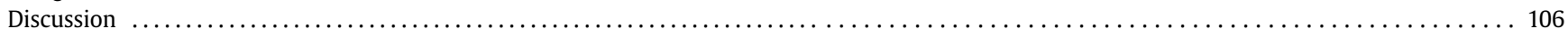

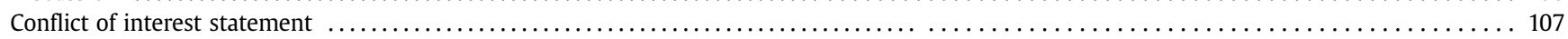

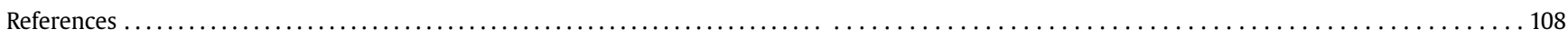

\footnotetext{
* Corresponding author. Department of Breast Surgery, Chris Obrien Lifehouse, Australia.

E-mail address: sanjay@drsanjaywarrier.com.au (S. Warrier).
} 


\section{Introduction}

Breast conserving therapy (BCT), which involves breast conserving surgery (BCS) and post operative radiotherapy, constitutes the standard treatment for early breast cancer. Six prospective RCT have demonstrated that the recurrence rate and survival outcomes are equivalent between mastectomy and BCT, with the latter having cosmetic advantages for breast cancer patients [6]. However, the lack of consensus on what constituted an adequate negative margin in BCS result in re-excisions to achieve wider negative margins, often at the cost of cosmesis.

A multidisciplinary consensus panel recently developed guidelines for the management of margins in patients with invasive breast cancer treated with BCT, based on the results of a metaanalysis of 33 studies including 28,162 patients [11]. Positive margins, defined as "ink on tumour", were associated with more that two-fold increase in the risk of ipsilateral breast tumour recurrence (IBTR) [6]. Therefore re-excision for positive margins is recommended. In contrast, wider margins than "no ink on tumour" do not significantly lower the risk of IBTR [11].

There is ongoing debate regarding the management of positive anatomically non-breast margins (anterior and deep margins). To date, there is no consensus regarding this practice. The motivation to identify reasons for re-excision is to reduce secondary operations and ultimately improve patient safety and care. Thus, the primary aim of this study was to investigate IBTR in patients who had reexcisions for PAM following BCS for stage I and II breast cancer. The secondary aim was to identify the re-excision rates among breast surgeons in this patient population.

\section{Methods}

\section{Literature search strategy}

A systematic literature review was performed through Ovid Medline, PubMed, Cochrane Central Register of Controlled Trials (CCTR), Cochrane Database of Systematic Reviews (CDSR), ACP Journal Club and Database of Abstracts of Review of Effectiveness (DARE) from January 1995 to July 2014. Relevant studies included those that discussed anatomical location of involved margins in breast conserving surgery. To achieve maximum sensitivity we combined the terms 'breast conserve*, 'surgery', "wide local excision', 'margin' and 'recurrence' as key words or MeSH terms. Studies were limited to human studies in English. Articles that did no describe margins according to anatomical location were excluded. Abstracts, case reports, conference presentations, and editorials were also excluded. Two independent investigators (E.D. and B.K.) screened abstracts identified in the literature search $(n=677)$ and full-text of potentially relevant studies $(n=143)$. All data were extracted from article texts, tables and figures. Two investigators (S.C.A. and G.T.) independently reviewed each retrieved article. Discrepancies between the two reviewers were resolved by discussion and consensus. The final results were reviewed by senior investigators S.W and H.C.

\section{Results}

\section{Quantity and quality of studies}

A total of 701 references were identified thorough the six electronic databases. After exclusion of duplicate or irrelevant references, 143 potentially relevant articles were retrieved for more detailed evaluation. After applying the selection criteria, six studies remained for assessment, three articles reported quantitative data and three articles contained qualitative results from cross-sectional surveys on this topic. The study selection process is presented in Fig. 1 according to the PRISMA statement.

\section{Quantitative studies}

In 2007, McIntosh et al. examined the risk of local recurrence in patients who had undergone BCS for stage I and II breast cancer with close margins (less than $2 \mathrm{~mm}$ ) or positive margins [9]. All patients in this study received adjuvant radiotherapy and did not undergo re-excision. Of the 200 patients that participated in this study, $71 \%$ of patients had close margins and $29 \%$ had positive margins, of which $23 \%$ had PAM. It was reported that the five and ten year risk of IBTR was 3\% and 5\% respectively, which is comparable to local recurrence rates in most series with adequate negative margins [9]. In addition, of the five local recurrences over a 71month follow up period, none of the patients had PAM following their initial operation.

More recently, Mullen et al. investigated the clinical benefit of re-excising a PAM following BCS by examining re-excised tissue for residual disease. This study examined 172 positive margins in 114 patients with one or more positive margins who subsequently underwent re-excision. Of the 49 patients with PAM who had a second operation, two (4\%) were found to have residual disease. In contrast, 18 of 23 patients (82\%) with positive radial margins were found to have residual disease and they underwent a mastectomy [12].

A large observational study by McCahill et al., in 2012 reported that $87.5 \%$ (42/48) of patients across four institutions with positive anterior or posterior margins underwent a re-excision. IBTR rates and residual disease in re-excised tissue were not reported [8].

\section{Qualitative studies}

Young et al. conducted a survey among 127 British breast surgeons on current practices in BCS in 2007. Responders chose between four options: do not re-excise/rarely/usually and definitely re-excise. The study reported that $71 \%$ of surgeons would not reexcise a negative anterior margin of $1 \mathrm{~mm}$. Of note, the survey also found that while $61 \%$ will not re-excise a PAM of less than $1 \mathrm{~mm}, 20 \%$ of surgeons would definitely re-excise a similar margin width [14].

A separate survey conducted in the United Kingdom in 2013 reported that $29.2 \%$ of the 281 breast surgeons who participated in the survey would never re-excise a close anterior margin in invasive breast cancer. It also reported that $61 \%$ of breast surgeons would routinely excise the overlying skin if the anterior margins were close to skin, compared to $28 \%$ of surgeons in 2007 [5].

In the United States, Blair et al. published a survey to investigate common practices in attaining a negative surgical margin in BCS. Breast surgeons could choose between never, sometimes, half the time, the majority of the time and always re-excise. The study reported that $53 \%$ of 351 surgeons would re-excise a PAM the majority of the time [1]. All three qualitative studies did not publish data to allow a direct comparison.

\section{Discussion}

Our findings indicate a paucity of studies exploring the anatomical location of positive margins and so far, there are no specific guidelines to approach the management of anatomically non-breast margins involved.

Surveys among British and American surgeons highlight the practice inconsistencies amongst surgeons regarding the decision to re-excise specific margins according to anatomical location, particularly in relation to a anterior and posterior margins. Comparison of the results of the survey among American breast 


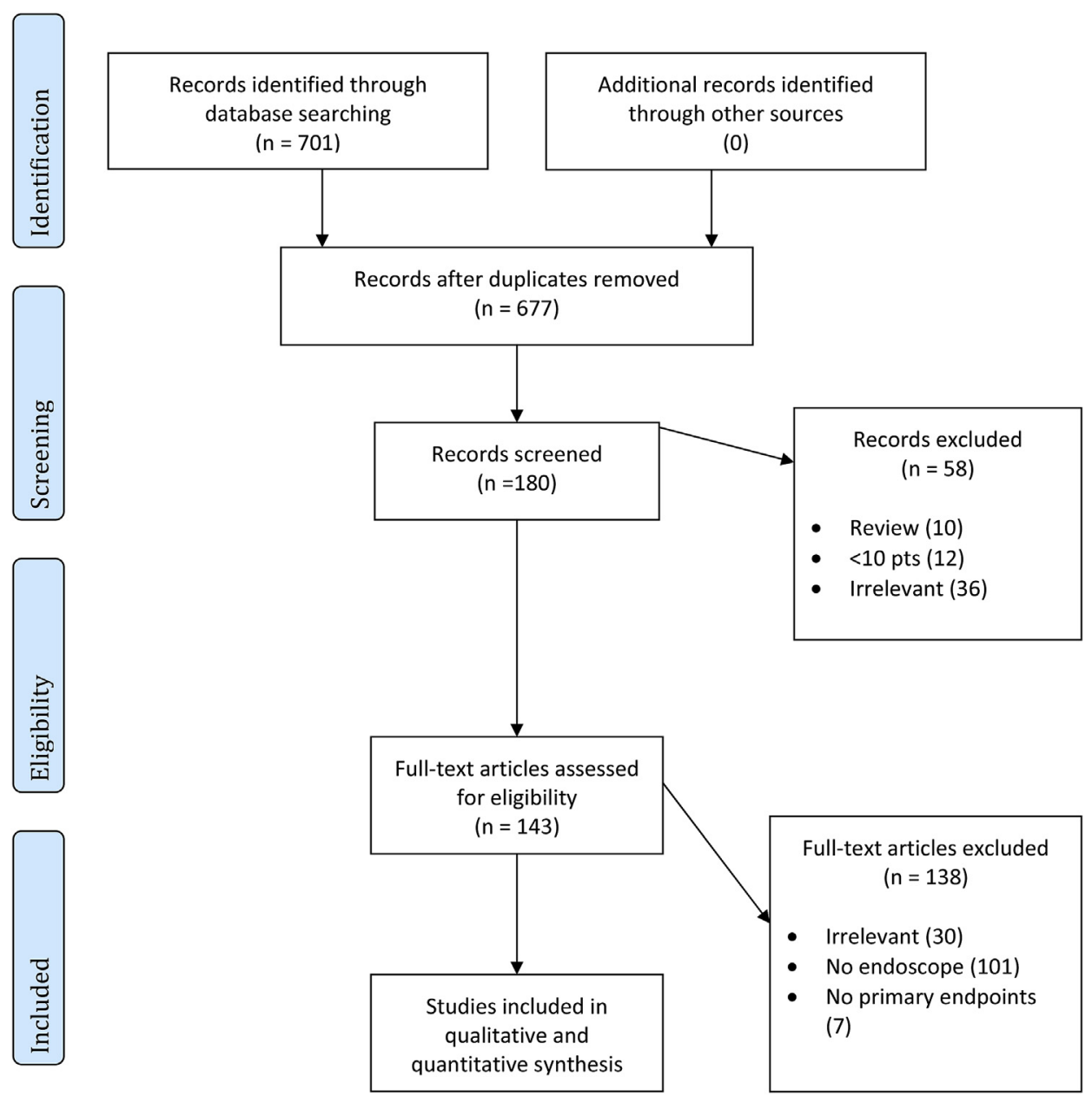

Fig. 1. Search strategy of systematic review.

surgeons with the observational study by McCahill et al. may indicate that surgeon intent and actual clinical practice do not necessarily have full correlation $[1,8]$.

The results of two retrospective studies showing a low IBTR rates in patients with PAM who did not undergo a re-excision and the low residual disease on re-excised tissues of patients with PAM, may support the hypothesis that a PAM does not warrant a reexcision. However this approach contradicts the recent consensus guideline, which encourages re-excision of positive margins [6,11].

Although the addition of adjuvant treatment (radiotherapy, endocrine therapy and chemotherapy) did not eliminate the difference of IBTR between a positive and negative margins [6], quantitative information on the amount of tumor at the margin was not included in these studies. It is likely that lower local recurrence rates are attributed to less residual breast tissue in anterior and posterior margins. This has been the rational for not re-excising a PAM, along with the fact that avoiding second operations reduces the likelihood of poor cosmetic results and additional stress for patients.

One of the major factors that may contribute to the varying reexcision rates between institutions is the problem of adequately orientating and identifying proper margins. This can be attributed to a number of factors including the method of orientation, size of specimen, tissue fixation time, specimen orientation, cold ischemia time, leaking ink, compression artifact or the 'pancake phenomenon' $[2-4,10]$. A British survey revealed that nearly $25 \%$ of breast units have no specimen orientation protocol despite the NHS Breast Screening Programme Guidelines [13]. Molina et al. reported an overall $31.1 \%$ disagreement rate between orientation marked by the surgeon and that performed by a pathologist. Specific analysis revealed that the deep and superficial (anterior and posterior) margins were associated with higher disorientation rates [10]. Specimen radiography such as intra-operative ultrasound and radioguided localization have demonstrated decreased positive margins in BCS [2].

The available literature to guide the approach to PAM in BCS currently is based on level III evidence. While current guidelines recommend re-excision of positive margins, current studies indicate there is limited benefit in re-excision of PAM in stage I and II breast cancer. Post operative discussions between the surgeon and pathologist should be held on a case-by-case basis within a multidisciplinary setting [7]. Further quantitative studies to investigate local recurrence in relation to anatomic location of margins are required, however this may be challenging given existing low IBTR and the long term follow up required for observational studies. Prospective studies with standardized specimen anatomical markings and reporting will provide more answers to aid better decision-making.

\section{Conflict of interest statement}

None declared. 


\section{References}

[1] Blair SL, Thompson K, Rococco J, Malcarne V, Beitsch PD, Ollila DW. Attaining negative margins in breast-conservation operations: is there a consensus among breast surgeons? J Am Coll Surg 2009;209(5):608-13. http:// dx.doi.org/10.1016/j.jamcollsurg.2009.07.026.

[2] Dooley WC, Parker J. Understanding the mechanisms creating false positive lumpectomy margins. Am J Surg 2005;190(4):606-8. http://dx.doi.org/ 10.1016/j.amjsurg.2005.06.023.

[3] Graham RA, Homer MJ, Katz J, Rothschild J, Safaii H, Supran S. The pancake phenomenon contributes to the inaccuracy of margin assessment in patients with breast cancer. Am J Surg 2002;184(2):89-93.

[4] Harness JK, Giuliano AE, Pockaj BA, Downs-Kelly E. Margins: a status report from the annual meeting of the American Society of Breast Surgeons. Ann Surg Oncol 2014;21(10):3192-7. http://dx.doi.org/10.1245/s10434-014-3957-2.

[5] Hassani A, Griffith C, Harvey J. Size does matter: high volume breast surgeons accept smaller excision margins for wide local excision-a national survey of the surgical management of wide local excision margins in UK breast cancer patients. Breast 2013;22(5):718-22. http://dx.doi.org/10.1016/j.breast.2012.12.009.

[6] Houssami N, Macaskill P, Marinovich ML, Morrow M. The association of surgical margins and local recurrence in women with early-stage invasive breast cancer treated with breast-conserving therapy: a meta-analysis. Ann Surg Oncol 2014;21(3):717-30. http://dx.doi.org/10.1245/s10434-014-3480-5.

[7] Krontiras H, Lancaster RB, Urist MM. What is a clear margin in breast conserving cancer surgery? Curr Treat Options Oncol 2014;15(1):79-85. http://dx.doi.org/10.1007/s11864-013-0270-4.
[8] McCahill LE, Single RM, Aiello Bowles EJ, Feigelson HS, James TA, Barney T, et al. Variability in reexcision following breast conservation surgery. JAMA 2012;307(5):467-75. http://dx.doi.org/10.1001/jama.2012.43.

[9] McIntosh A, Freedman G, Eisenberg D, Anderson P. Recurrence rates and analysis of close or positive margins in patients treated without re-excision before radiation for breast cancer. Am J Clin Oncol 2007;30(2):146-51. http://dx.doi.org/10.1097/01.coc.0000251357.45879.7f.

[10] Molina MA, Snell S, Franceschi D, Jorda M, Gomez C, Moffat FL, et al. Breast specimen orientation. Ann Surg Oncol 2009;16(2):285-8. http://dx.doi.org/ 10.1245/s10434-008-0245-z.

[11] Moran MS, Schnitt SJ, Giuliano AE, Harris JR, Khan SA, Horton J, American Society for Radiation, O. Society of surgical Oncology-American society for radiation Oncology consensus guideline on margins for breast-conserving surgery with whole-breast irradiation in stages I and II invasive breast cancer. J Clin Oncol 2014;32(14):1507-15. http://dx.doi.org/10.1200/JCO.20 13.53.3935.

[12] Mullen R, Macaskill EJ, Khalil A, Elseedawy E, Brown DC, Lee AC, et al. Involved anterior margins after breast conserving surgery: is re-excision required? Eur J Surg Oncol 2012;38(4):302-6. http://dx.doi.org/10.1016/ j.ejso.2012.01.004.

[13] Volleamere AJ, Kirwan CC. National survey of breast cancer specimen orientation marking systems. Eur J Surg Oncol 2013;39(3):255-9. http://dx.doi.org/ 10.1016/j.ejso.2012.12.008.

[14] Young OE, Valassiadou K, Dixon M. A review of current practices in breast conservation surgery in the UK. Ann R Coll Surg Engl 2007;89(2):118-23. http://dx.doi.org/10.1308/003588407X155473. 